\title{
GENERAL CONCERNS LIFE-CYCLE DESIGN OF ECONOMICAL ICE-RESISTANT STRUCTURES IN THE BOHAI SEA
}

\author{
ZHANG Da-yong, Prof. Dr., \\ YU Song-song, Ph. D., \\ YUE Qian-jin,Prof. Dr., \\ Dalian University of Technology, China
}

\begin{abstract}
In China, the oil and natural gas resources of Bohai Bay are mainly marginal oil fields. It is necessary to build both iceresistant and economical offshore platforms. However, there are many risks during the life cycle of offshore platforms due to the imperfect preliminary design for the Bohai Sea economical ice-resistant structures. As a result, the whole life-cycle design should be considered, including plan, design, construction, management and maintenance design. Based on the demand of existing codes and research of the basic design, structural ice-resistant performance and the reasonable management and maintenance, the life-cycle design theory is discussed. It was concluded that the life-cycle cost-effective optimum design proposed will lead to a minimum risk.
\end{abstract}

Keywords: ice zone; economical ice-resistant structure; life-cycle design; performance-based design; cost-effective code

\section{INTRODUCTION}

The Bohai oil fields belong to the marginal oilfields, with ice load being the main control load. Considering the developing cost of Bohai offshore marginal oilfields, an economical ice-resistant platform should be adapted. At present, the technology in design and construction is not mature enough, and there are many defects including the following: (1) There is no clear dynamic ice load under the extreme static ice force; (2) It does not take into account the ice-induced vibration of the structure under dynamic failure modes; (3) The parameters of sea ice are not perfect, especially the ice fatigue environmental parameters; (4) The pattern of ice-resistant structures is not clear; and (5) The design method is still the traditional way of trial-check-modify, etc [1]. Based on monitoring, there were numerous problems with the platform once it goes into action. It brings an adverse impact on structure safety, operation personnel safety and facilities [2]. In addition, as is the case in a marine environment, operation and construction load is complex. There are many uncertainties and risks throughout the design, construction, operation, management and maintenance, failure scrap, and the whole service period. For example, due to of the environmental load randomness and seawater corrosion etc., resistance performance of an offshore platform structure will be degraded over time. In the process of installation and use, there will be different degrees of damage and defects for platforms, etc. Therefore, in designing the Bohai Sea economical ice structure, we must change the focus from the platform construction completion 
status to planning, designing, construction and maintenance during the whole life cycle process.

The life cycle of the ice-resistant structures includes oil block planning, lectotype design, performance design, detail design, construction, operation, management and maintenance, failure scrap, etc. Among them, the design phase is the most critical stage of building and optimizing the structure scheme to transform the requirements of owners, users and society to technical system performance. The core idea of life cycle theory is to consider all sorts of problems and project content in the follow-up stage in front of the specific engineering in order to achieve the desired optimal goal [3]. Based on the demand of the existing codes and the research of the basic design, considering the structural ice-resistant performance and the reasonable management and maintenance, the lifecycle design theory is discussed. It was concluded that the life-cycle cost-effective optimum design proposed will lead to a minimum risk.

\section{FRAMEWORK FOR LIFE-CYCLE DESIGN OF ECONOMICAL ICE-RESISTANT STRUCTURES}

Life-cycle design of economical ice-resistant structures has three main parts: lectotype design, structural performance design and management and maintenance design. Fig. 1 provides the framework for lifecycle design of economical ice-resistant structure. Lectotype design is a primary consideration within the overall design. Because many uncertainties and risks exist in the design of

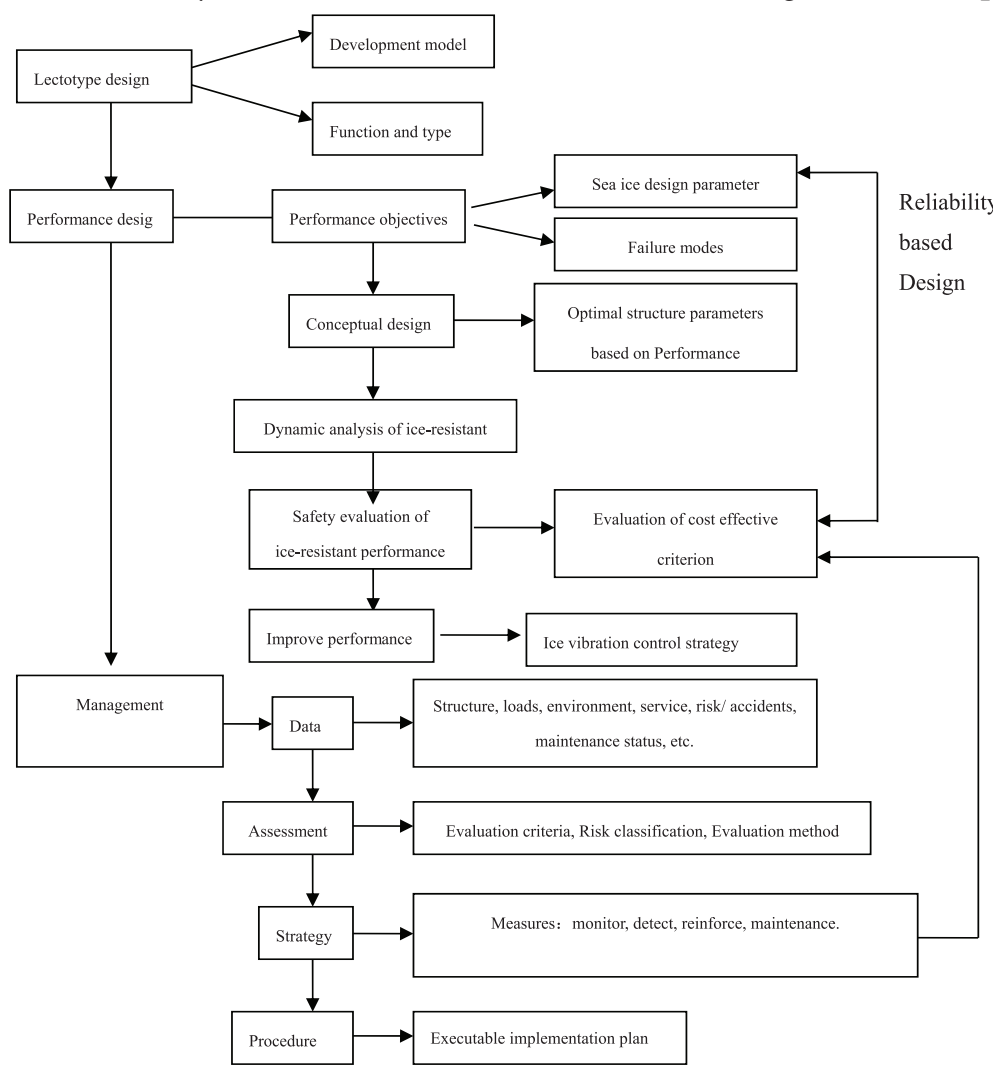

Fig. 1. Conceptual frame of life-cycle based economical ice-resistant structures design performance and management and maintenance, the loss should be estimated reasonably. The paper discusses these key problem about life-cycle design of economical ice-resistant structures.

\section{LECTOTYPE DESIGN}

Due to coupling between ice and structures, type, size and formation of ice are related to the structural type. Some other closely related factors are marine environment, ice condition, oil reservoir distribution, pattern development and people's understanding of ice-resistant structures. Thus, lectotype is an important aspect of the life-cycle design of economical iceresistant structures. A number of factors should be taken into account during the design process of economical structures including platform functions, economy, environmental factors, wells, collection terms, transport capacity, etc. Under the same conditions, designers provide a variety of different schemes. The result is economic structures that come in several forms with no fixed pattern. Lectotype design needs to be based on the fields development planning, structure function and ice-resistant capability.

Cold region marginal fields can be developed in several ways: (1) Joint development of little oilfields in groups; (2) Mono-hull modes of production; (3) Extended reach well drilling; and (4) Submarine wellhead system. Among these developments, joint development of little oilfields in groups is a general pattern [4]. Development strategy principles include maximization of resources, decreased investment and allowing complete development of the integrated function of center platforms. Then, the center platform can become multi-functional and can be used in production, management, crude output, providing power and living. For the development of the Satellite Oilfield, simple platforms should be adopted as much as possible. The principle is that crude oil, which heads from oilfield groups, is transported from center platforms to shore side terminals through submarine pipelines or shuttle tankers. The development scheme is as follows: (1) the jacket platform (center platform) and wellhead platform (satellite platform) and Submarine pipeline; (2) the jacket platform (center platform) and wellhead platform (satellite platform) and FPSO and shuttle tankers. This article is based on the monitoring and detailed analysis for iceresistant structures in Liaodong Bay of the Bohai Sea. Economical ice-resistant structures that fit into the Bohai Bay marginal fields are discussed (see Table 1.). 
Tab. 1. The type and classification for proper economical ice-resistant platforms

\begin{tabular}{|c|c|c|c|}
\hline Function & Platform type & $\begin{array}{l}\text { Water depth } \\
\qquad(\mathrm{m})\end{array}$ & $\begin{array}{c}\text { Classifica- } \\
\text { tion }\end{array}$ \\
\hline $\begin{array}{l}\text { center } \\
\text { platform }\end{array}$ & Four leg jacket & $10-30$ & I \\
\hline \multirow{2}{*}{$\begin{array}{l}\text { satellite } \\
\text { platform }\end{array}$} & $\begin{array}{c}\text { Three leg } \\
\text { jacket }\end{array}$ & $10-30$ & \multirow{2}{*}{ II } \\
\hline & $\begin{array}{c}\text { Single-leg } \\
\text { jacket }\end{array}$ & $10-20$ & \\
\hline $\begin{array}{l}\text { auxiliary } \\
\text { structure }\end{array}$ & $\begin{array}{l}\text { bucket foun- } \\
\text { dation with a } \\
\text { single pillar }\end{array}$ & $<10$ & III \\
\hline
\end{tabular}

\section{STRUCTURAL PERFORMANCE BASED DESIGN}

The goal in designing performance by ice loads is to control the structural safety and usability effectively and to clear the performance of the structure in different intensities. Based on the ideology of performance based design, we can realize the prescribed requirements using different means and methods by addressing the limitations of design code and admissible structural performance designs, as shown in Fig. 1.

\section{STRUCTURAL ICE-RESISTANT PERFORMANCE OBJECTIVES}

Based on the monitoring of ice-resistant structures in Liaodong Bay, Zhang and Yue [5] set up the failure mode and determined performance requirements of economical ice-resistant platforms, as shown in Fig. 2.

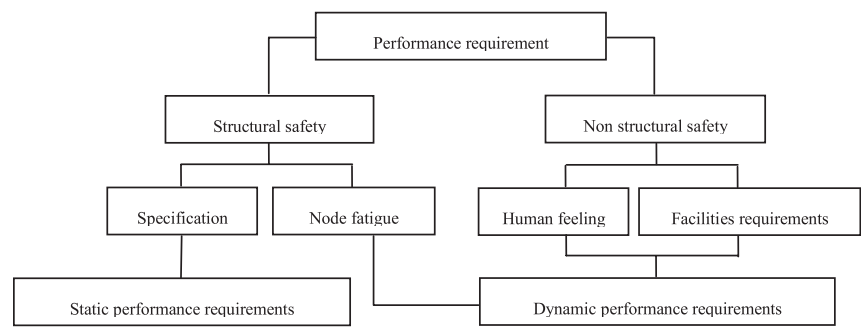

Fig. 2. Performance requirements of economical ice-resistant platforms

The performance definition of economical ice-resistant platforms in the Bohai Sea is described in Table 2. It mainly contains the following:

(1) Structural safety failure mode, which includes the excess of the maximum deformation or strength of the structure to the threshold values under extreme static ice load and fatigue damage of tubular joints under ice-induced vibrations.

(2) Human factor failure mode, which may cause the physical discomfort, affect the work efficiency, and even endanger the health of the crew members due to significant vibration of platform deck.
(3)Facilities failure mode, which refers to the unserviceability or damage of the facilities on the platforms caused by ice-induced vibrations, such as fatigue fracture of pipes and looseness of flanges.

There are some concerned stipulations about the security of ice-resistant jacket platforms under extreme static ice loads in the current design criterion [6,7]. However, specification only proposed the necessity of analyzing fatigue failure. The failure of personnel comfort and ice-induced vibration of facilities is not considered in the code.

Tab. 2. Discriminant index of ice-resistant platform failure modes

\begin{tabular}{|c|c|c|}
\hline $\begin{array}{l}\text { Failure } \\
\text { type }\end{array}$ & Performance description & Failure discrimination index \\
\hline \multirow{2}{*}{ 苞 } & $\begin{array}{l}\text { Structural safety damage } \\
\text { under } \\
\text { an extreme static ice load }\end{array}$ & $\begin{array}{l}\text { Structural deformation, stress } \\
\text { or } \\
\text { reserve strength coefficient }\end{array}$ \\
\hline & $\begin{array}{c}\text { Structural fatigue damage } \\
\text { under } \\
\text { a dynamic ice load }\end{array}$ & Alternating stress of hot spot \\
\hline \multirow[t]{2}{*}{ 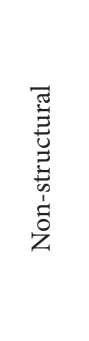 } & $\begin{array}{l}\text { Physical discomfort, } \\
\text { degraded work } \\
\text { efficiency, and even } \\
\text { endangerment of } \\
\text { health of crew members } \\
\text { induced by } \\
\text { deck platform }\end{array}$ & $\begin{array}{c}\text { Equivalent deck acceleration, } \\
\text { frequency, duration, and } \\
\text { direction. }\end{array}$ \\
\hline & $\begin{array}{l}\text { Endangerment of health of } \\
\text { crew members induced by } \\
\text { deck intensive vibration }\end{array}$ & Deck acceleration \\
\hline
\end{tabular}

\section{ICE LOAD AND SEA ICE PARAMETERS}

\section{ICE LOAD}

In the life-cycle design of economical iceresistant structures, ice load requires calculations of the extreme ice force and dynamic ice force. There are many formulas for calculating the extreme ice force, and the effects of leg type should be considered. There are two typical calculation formulas of the extreme ice force: the API standard formulas and the Hirayama - Obara ice-force model [8]. There is no exact formula for dynamic ice force in design standards. Based on field measurements of the interaction between ice and vertical structures and integrating with pulsating wind spectrum research, Kärnä et al. [9] established the extrusion of random ice force spectrum model. The function is:

$$
S(f)=\frac{7.2 \sigma^{2}}{1+10.4 \times 7.2^{1.5} f^{2}}
$$

where $\sigma$ is the ice force variance; $f$ is the ice load frequency.

According to the time-history curve, which is based on field measurements of the interaction between ice and vertical structure, Yue and $\mathrm{Bi}$ [10] established a deterministic ice force function. The function is as follows: 


$$
F(t)=\left\{\begin{array}{cc}
F_{0}\left(1-\frac{t}{\tau}\right) & (0 \leq t<\tau) \\
0 & (\tau \leq t<T)
\end{array}\right.
$$

where $F_{0}$ is the amplitude of ice force; $\tau$ is the time of ice force.

According to the data measured from filed, Yue et al. [11] established a spectral function of ice force on conical structures through the analysis of the frequency spectrum. The function is expressed as follows:

$$
S(f)=\frac{10.88{\overline{F_{0}}}^{2} \bar{T}^{-2.5}}{f^{3.5}} \exp \left(-5.47 \bar{T}^{-0.64} \frac{1}{f^{0.64}}\right)
$$

where $F_{0}$ is the amplitude of the ice force on conical structures; $\mathrm{T}$ is the cycle of ice force.

\section{SEA ICE ENVIRONMENTAL PARAMETERS}

Sea ice environmental parameters in the environmental fatigue arena are based upon ice thickness, ice strength and speed, flow direction of ice and probability distribution characteristic of the ice age. Based on observed winter sea ice from 1996 to 2004 in Liaodong Bay, the main statistical properties of sea ice environmental parameters have been given by Ji et al. [12]. Among them, ice thickness obeys a logical normal distribution (Eq. (4)), ice speed follows a Rayleigh distribution (Eq. (5)) and ice strength is normally distributed.

$$
\begin{gathered}
f(h)=\frac{1}{0.5503 h \sqrt{2 \pi}} \exp \left[-\frac{1}{2}\left(\frac{\ln h-1.9764}{0.5503}\right)^{2}\right] \\
f\left(v_{i}\right)=\frac{v_{i}}{826.5512} \exp \left(-\frac{v_{i}^{2}}{1653.1024}\right)
\end{gathered}
$$

where h is the ice thickness; $v$ is the ice speed.

The flow direction of the ice is related to the geographic location, terrain, wind, current, and other relevant factors. Based on measured data, two major trends $\left(45^{\circ}\right.$ and $225^{\circ}$ ) were adopted in the actual computation.

\section{THE CONCEPTUAL DESIGN OF ICE-RESISTANT STRUCTURES}

The vibration of ice-resistant jacket structures under ice loads is focused on the natural frequency. The variation of the first mode is mainly due to changes in the level of direction. Therefore, complex offshore platforms can be simplified into spring-mass systems with a single degree of freedom. Offshore platforms were simplified into equivalent nonlinear systems with a single degree of freedom by a static nonlinear pushover method [13]. Based on scene monitoring and numerical simulation analysis, the structural response does not reach its plastic response stage and is mainly in the elastic response under ice load. The decision was therefore made to (1) To assume that infrastructure distributed mass and superstructure weight were equivalent to the center of gravity of the platform deck; (2) To simplify the platform legs as elastic rods that cannot be elongate with equivalent stiffness (as shown in Fig. 3).

In Fig. 3, $\mathrm{Ke}$ is the equivalent stiffness of the simplified mechanics model. The generalized force (concentrated force and uniform force or torque) induces the unit generalized displacement in the vertex of the platform structure (horizontal displacement or angular displacement). $\mathrm{M} e$ is equivalent mass. The modified method was adopted. The mass of the jacket ( $\mathrm{ml}$ ) was used as a concentrated mass added to the superstructure mass. Then, the equivalent mass is $\mathrm{Me}=\mathrm{m}+\mathrm{m} 1 / 3$. Thus, the angular frequency of the platform structures can be determined:

$$
\omega_{n}=\sqrt{\frac{K_{e}}{M_{e}}}
$$

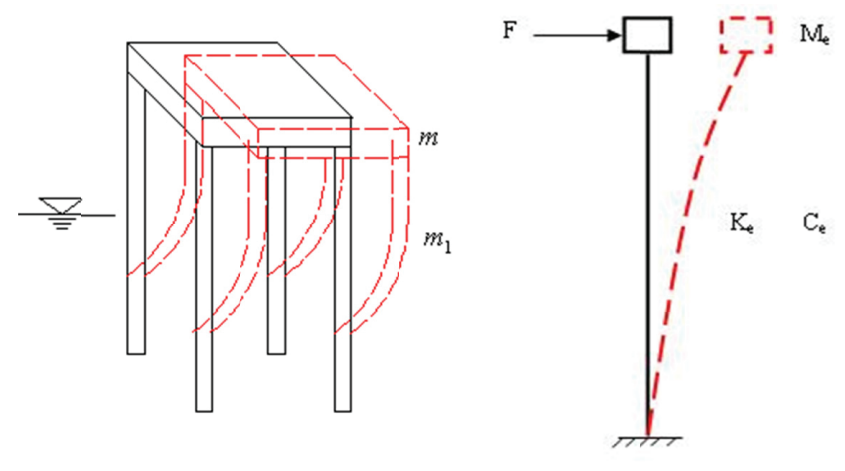

Fig. 3. Conceptual model of economical ice-resistant structures

$\mathrm{Ke}$, Me and $\mathrm{C} e$ can excellently express mechanical models of economical ice-resistant structures. A certain linear relation exists between $\mathrm{K} e$ and the mass of steel $\left(\mathrm{m}_{1}\right)$ by Zhang et al. [14]. The conceptual model can be adopted in implementing an optimal match between the superstructure weight of the iceresistant platform $(\mathrm{m})$ and $\mathrm{m} 1$. The optimizing model is::

$$
\begin{aligned}
& \text { find } \quad m_{1} \\
& \mathrm{~m} \text { in } m \\
& \begin{aligned}
U & \leq[U] \\
\text { s.t. } \quad a_{r \cdot m \cdot s, a} & \leq\left[a_{r . m, s, a}\right]
\end{aligned} \\
& \omega_{n} \neq \omega_{\text {ice }}
\end{aligned}
$$

The maximum lateral displacement $U$ is used to evaluate static performance under the extreme static ice load, namely, $U=\frac{F}{K} \leq[U]$, where $\mathrm{F}$ is the extreme static ice load, $\mathrm{K}$ is the equivalent lateral stiffness and $[U]$ is the allowable lateral displacement of structure. Because of the inherent dynamic characteristic of ice load and the ice-resistant structure, 
the interaction coupling between ice and the structure may produce significant ice-induced vibration. Therefore, with respect to structural vibration properties, the jacket structures of natural frequency should take these considerations into account. This means that jacket platform structure should avoid consistent with sea-ice frequency $\left(\omega_{i c e}\right)$. On the other hand, we also should consider ice-induced vibration problems that can be evaluated by the ice-induced vibration acceleration mean square value $\left(a_{r . m . s, a}\right)$ under the dynamic ice force.

\section{ICE-RESISTANT DYNAMIC ANALYSIS}

Due to the performance-based design targets, different dynamical analyses of structures need to meet different performance requirements. Effective and reasonable calculations can improve and perfect initial concept designs. Depending on the different ice-resistant performance, the dynamical analysis of structure includes problems considering staff morale under the ice-induced vibration, analyzing fatigue of ice-induced vibration structure and analysis of the upper line ice-induced vibration response.

There are currently few studies abroad about the fatigue of ice-induced structure vibration. Fang et al. $[15,16]$ developed appropriate research in China. Based on the work considering ice load, Yue et al. [17] proposed two main problems in the analysis: the fatigue ice load and fatigue environmental parameters. Zhang et al. [18] proposed a method for fatigue life calculation of an ice-induced vibration jacket platform.

The influence of vibration on staff is primarily defined by the vibration acceleration amplitude on the deck, vibration frequency, vibration and direction of vibration. We can set boundaries for three types of evaluation indices according to the above four factors. After years of vibration monitoring, we found that the ice-induced vibration direction of the platform is horizontal, and the vibration is mainly focused on the fundamental frequency of the platform. We also found that the fundamental frequency of the jacket platform is generally in the range of $1-2 \mathrm{~Hz}$. We should make more explicit the vibration acceleration amplitude and duration according to measurements and numerical simulation. Then, we can give the evaluation of ice-induced vibration of staff as well as recommended specifications in Table 3 [19].

The superstructure design of ice-resistant platforms does not take into account the ice-induced vibration. The specifications in the recommended practice of offshore fixed platform planning, designing and construction rules state that superstructures can be simplified to the simplest form for the analysis of platform jackets or infrastructure. However, the vertical and horizontal stiffness and the corresponding effects should be first ascertained. The superstructure itself can be analyzed as one or more independent structures according to the construction situation. However, the influence of structure displacement should be considered in the simulation of boundary supports [20].

\section{MANAGEMENT AND MAINTENANCE DESIGN}

There are many threats of ice and potential safety hazards for the Bohai Sea economical ice-resistant structures in winter operation. The sea ice management for the oilfields in Liaodong Bay of the Bohai Sea ensures safe operation is a strategy for safety management and maintenance. At present, countries around the world are particularly concerned with monitoring, maintenance and repair, etc. of the special structures with operation risk such as bridges, pipeline engineering, etc. Consideration of the management and maintenance stage could be a part of the design document from the start of the design stage. The designing method as well as the management and maintenance stage can be mutually conditional and can reflect the thought of life-cycle design in the highest degree. The final aim of the management and maintenance design is to reduce life cycle cost. Therefore, foreign researchers have established a quantitative calculation model of the cost of management and maintenance. However, it is difficult to implement. The aim of the design is to build the overall project of management and maintenance. This paper suggests design flows of economical ice-resistant structures

Tab. 3. Critical value of human sensation based on the relationship between the vibration acceleration and duration for different levels of vibration

\begin{tabular}{|c|c|c|c|c|c|c|c|c|c|}
\hline & $24 \mathrm{~h}$ & $16 \mathrm{~h}$ & $8 \mathrm{~h}$ & $4 \mathrm{~h}$ & $2.5 \mathrm{~h}$ & $1 \mathrm{~h}$ & $25 \mathrm{~min}$ & $16 \mathrm{~min}$ & $1 \mathrm{~min}$ \\
\hline I & 0.03 & 0.05 & 0.07 & 0.11 & 0.16 & 0.27 & 0.4 & 0.48 & 0.63 \\
\hline II & 0.095 & 0.158 & 0.221 & 0.347 & 0.504 & 0.851 & 1.26 & 1.512 & 1.985 \\
\hline III & 0.19 & 0.316 & 0.442 & 0.694 & 1.008 & 1.702 & 2.52 & 3.024 & 3.97 \\
\hline
\end{tabular}

[Note]: I is the comfort degradation boundary, II is the work efficiency degradation boundary, and III is the exposure limitation. III is 3.15 times as great as I and twice as great as II. 
and is shown in Fig. 1. The integrity management of structural systems includes database, evaluation, policy and program.

The primary aspect of the management and maintenance design process is updating platform information, which requires original design/evaluation, construction and installation information. The data can be summarized in two categories:

(1) Feature data: the basic information platform (lifetime, design depth, sea ice conditions, etc.) and the design, build and the relevant data of installation;

(2) Conditional data: variable data during the operation of the platform, such as platform modification, detection, damage, etc.

Process evaluation includes assessment criteria, risk rating and evaluation methods. Among them, assessment criteria can reference performance requirements (see Tab. 2). Risk grades of economical ice-resistant structures are divided into four levels:

Level I signifies structure capsizing or settling under extreme loads;

Level II represents pipe nodes of structure fatigue fracturing;

Level III is pipeline failure under ice-induced vibration;

Level IV is personnel comfort requirements.

Evaluation methods, which refer to Chapter One, include: safety of the structure, personnel comfort requirements and normal operation of the superstructure. Based on safety management of ice-resistant jacket structures in Liaodong Bay of the Bohai Sea, different levels of risk require different measures of management and maintenance, as shown in Table 4.

In order to achieve the minimum life cycle cost of the structures, an optimal strategy of management and maintenance design needs to be developed. It includes choice of monitoring (check) points, the optimal number, test cycle, etc. Difficulty in utilizing an optimal strategy of management and maintenance design lies in considering the uncertainty and model of reliability that should be adopted. At present, Li et al. [13], Zhang et al. [21], Li et al. [22] built structural reliability models under an extreme static ice load, a probabilistic model of ice-induced vibration acceleration failure and a reliability model of time-varying node fatigue, respectively.

\section{EVALUATION OF COST-EFFECTIVE CRITERION}

The basic principle behind economical ice-resistant structures is the evaluation of the cost-effective rule. It underlines that thoughts change from focusing on the integral safety of structures to performance, safety, economics, etc. Based on this criterion, the design of economical ice-resistant structures is based on minimizing the cost of the life cycle according to ice-resistant performance, comprehensive management, maintenance, etc. The total cost includes the initial cost of the structures in addition to risk costs. Structural risk, structural properties (including ice load, properties of structural materials, structural components resistance force, etc.) and structural mechanics analysis models involve much uncertainty. Therefore, the design process should adopt reliability methods that reasonably estimate the economy of the project (project investment, the cost of management and maintenance, losses caused by ice disaster, etc.). Li et al. [23] analyzed the relationship between the weight of steel in structures and the initial resistance based on typical jacket structures in Bohai. The results show that the steel weight of structures and initial resistance meet certain linear relationships. It determines the assessment model of total cost and loss value evaluation methods of structures under ice load. It provides a reasonable basis for social-economic, comprehensive evaluations for economical ice-resistant structures.

\section{CONCLUSIONS}

Research on the basic design of economical ice-resistant structures in Bohai provides a framework for the life cycle of high risk ice-resistant structure design. Based on the existing specification requirements for Bohai structures and the research results obtained in the basic design, the core idea was to highlight the performance requirements to reduce the structural risk to a minimum through reasonable management and maintenance. This paper studied the relevant content, including proposing suitable design elements for the cold and marginal oilfield development for economic ice-resistant structure types, which are based on the analysis and monitoring in Liaodong Bay of Bohai. The performance requirements of the economical ice-resistant platforms were defined, and the index was given. The concept model of the economic structure was established. The optimal matching of the mass of the superstructure and the quality of the jacket were further considered.

Based on the research of ice load and environmental parameters in the design of ice structures, we presented the process and the basic content of the investment-benefit criterion, as well as the investment benefit criterion during the life cycle design .The research of this paper provides a scientific basis for the whole life design of the economic structures in Bohai.

Tab. 4. Management and maintenance measures of economical ice-resistant structures

\begin{tabular}{|c|c|c|c|c|c|}
\hline Risk & human feeling & pipeline operation & $\begin{array}{c}\text { structure fa- } \\
\text { tigue }\end{array}$ & foundation settlement & foundation overturn \\
\hline $\begin{array}{c}\text { Mea- } \\
\text { sures }\end{array}$ & monitor & monitor /detect & detect & monitor & reinforce / maintenance \\
\hline
\end{tabular}




\section{ACKNOWLEDGEMENTS}

The support of the National Natural Science Foundation of China (51679033, 51309046), State's Key Project of Research and Development Plan (2016YFC0303400), the Special items of national marine public welfare industry (201505019) are much appreciated.

\section{BIBLIOGRAPHY}

1. Gang Li, Dayong Zhang, Qianjin Yue.: Minimum life-cycle cost design of ice-resistant offshore platforms. Structural Engineering and Mechanics, 31(1), 2009, p.11-24.

2. Zhang Dayong, Xu Ning, Yue qianjin, Liu Di.: Sea ice problems in Bohai Bay oil and gas exploitation. Journal of coastal research, 73, 2015, p.676-680.

3. Dimitri V. Val and Mark. G. Stewart.: Life-cycle cost analysis of reinforced concrete structures in marine environments. Struct. Safety, 25, 2003, p.121-130.

4. Zheng Hongyin.:Methods for high efficiency development of offshore oil and gas fields in China. Journal of oil and gas technology, 27(5), 2005, p.784-786.

5. Zhang Dayong, Yue Qianjin.: Major challenges of offshore platforms design for shallow water oil and gas field in moderate ice conditions. Ocean Engineering, 38, 2011, p.1220-1224.

6. API RP-2A WSD.: Recommended practice for planning, design and constructing fixed offshore platforms-working stress design. API Recommended Practice 2A-WSD, 21 Edition, 2000.

7. ISO/DIS 19902.: Design of fixed steel jackets. DIS Draft. International Standardization Organization, 2004.

8. Hirayama K, Obara I.: Ice forces on inclined structures. Proc of the 5th International Offshore Mechanics and Arctic Engineering, Tokyo, Japan, 1986, p.515-520.

9. Kärnä T, Qu Yan, et al.: A spectral model for forces due to ice crushing. Journal of Offshore Mechanics \& Arctic Engineering, 129, 2007, p.138-145.

10. Yue, Q.J., Bi, X. J.: Full-scale Tests and Analysis of Dynamic Interaction between Ice Sheet and Conical Structures. Proc. of 14th IAHR, Potsdam, 2, 1998, p.939-945.

11. Yue, Q.J., Qu, Y., Bi, X.J., Kärnä, T.: Ice Force Spectrum on Narrow Conical Structures. Cold Regions Science and Technology, 49, 2007, p.161-169.

12. S. Y. Ji, Q. J. Yue, X. J. Bi.: Probability distribution of sea ice fatigue parameters in JZ20-2 sea area of the Liaodong Bay. The Ocean Engineering, 20(3), 2002, p.39-43.

13. Li G, Zhang DY, Yue QJ.: Efficient approximate method of the global reliability analysis for the offshore platforms in ice zone., China Ocean Engineering, 22(2), 2008, p.303-312

14. Zhang Dayong, Li Gang, Yue Qianjin.: Statistical properties of structural global resistance and extreme response of offshore platform in ice zone. Shipping mechanics, 17(1-2), 2013, p.112-117.

15. H. C. Fang, F. Y. Xu, G. M. Chen.: A new method for fatigue life calculation of tubular joint of offshore platform in ice region. China offshore platform, 12(6), 1997, p.259-263.

16. H. C. Fang, M. L. Duan, F. Y. Xu.: Reliability analysis of ice-induced fatigue and damage in offshore engineering structures. China ocean engineering, 14(1), 2000, p.12-24.

17. Q. J. Yue, Y. Liu, Y. Qu, Z. M. Shi.: Fatigue-life analysis of ice-resistant platforms. Engineering Mechanics, 24(6), 2007, p.159-164.

18. Zhang Dayong, Liu Di, Xu Ning, Yue Qianjin.: Fatigue life analysis of the vertical leg jacket platform induced by ice vibrations. The ocean engineering, 33(4), 2015, p.35-44.

19. GB/T13442-92.: Reduced comfort boundary and evaluation criteria for human exposure to whole-body vibration. 1992.

20. Zhang Dayong, Yue Qianjin, Che Xiaofei.: The Effects of Facilities and Crew Members on the Ice-resistant Platforms Induced by Ice Vibrations in Bohai Sea. The 21st International Offshore (Ocean) and Polar Engineering Conference, Maui, Hawaii, USA, 2011, p.19-24.

21. Zhang Dayong, Li Gang, Yue Qianjin.: Dynamic reliability analysis of human exposure to ice-induced vibration on offshore platforms. China offshore platform, 21(3), 2006, p.40-44.

22. Li Gang, Zhang Dayong, Yue Qianjin.: Time-dependent fatigue reliability analysis of offshore platforms in ice zone. Chinese journal of computational mechanics, 23(5), 2006, p.513-517.

23. Li Gang, Zhang Dayong, Yue Qianjin.: Life-cycle cost-effective optimum design of offshore platforms considering environmental stressors in ice zone. Journal of Offshore Mechanics and Arctic Engineering, 131, 2009, p.031501-031509. 


\section{CONTACT WITH THE AUTHOR}

ZHANG Da-yong, Prof. Dr.

e-mail:zhangdy@dlut.edu.cn

School of Ocean Science \& Technology

Dalian University of Technology

Panjin

CHINA 